\title{
UNCERTAIN OBSERVER-ATTENTIVE PRACTICES FOR THREATENED NONHUMANS
}

Madison Kelly

In Sorawit Songsataya's The Interior (2019)', bird species of Aotearoa New Zealand, gathered in stillness on the outside deck of Toi o Tamaki Auckland Art Gallery, observe the form of a fallen moa. The avian communion, rendered three dimensional in fiberglass, polyester resin, acrylic lacquer, and Oamaru stone, offers navigable space for visitors (human observers) to join them in their looking. The gallery's statement about the work suggests its function as an inversion of classical human/nonhuman relations, inwardly turning our "often fraught relationship with the natural world...typically defined by 'the outside' or by remoteness".

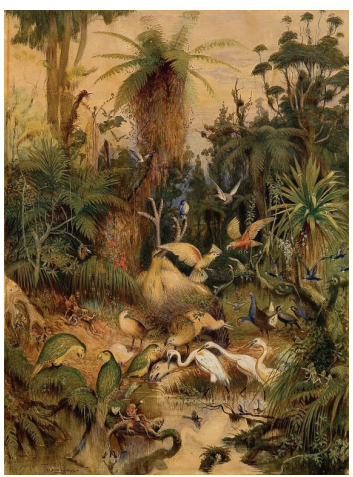

Figure I. Trevor Lloyd, Te tangi o te moa, 1907, watercolour, $520 \times 380$ mm. Auckland Art Gallery Toi o Tāmaki, bequest of Miss Connie Lloyd. Auckland Art Gallery, accessed June 16 2020. (www.aucklandartgallery. com/explore-art-and-ideas/ artwork/5907/te-tangi-o-te-moa)
From the human "inside", looking towards the animal "outside", the trope of a fixed representational porthole as visual incision into "wild" space has long been used to set up nonhuman worlds as othered and unchanging sites. Certainly, the painting referenced in The Interior, Trevor Lloyd's Te Tangi o Te Moa (1907, Figure I), ascribes to such an ideal, offering through strategies of history, landscape, and fantasy painting, an anthropocentric glimpse into both the enigmatic lives of the "wild" bush, and the moa's own extinction around 600 years ago. As a record of attention towards an extinction event, Te Tangi o Te Moa presents a singular presumption, one of many "competing constructions" typical to our understandings of extinct species, those creatures evocative of not only "scientific enquiry" but "fantasy [and] the projection of cultural values" as described by Phillip Armstrong in his essay Moa Ghosts. ${ }^{3}$

A representation of (imagined) exterior looking, Te Tangi finds methodological kin in fields reliant upon observation as a knowledge-producing tool (the natural sciences, and the institutions of animal display they have borne: museums, dioramas, scientific illustrations, and zoos). Operating under the facade of objective viewing, observation here acts as a tether to certainty. Microbiologist Margaret McFall Ngai acknowledges such in her writing on advancements in microbial observation, noting "our understanding of the biological world has always been fundamentally linked to how we are able to perceive it". ${ }^{4}$ With growing and ever more attentive records of looking, however, new questions emerge across fresh scales, and with them, new uncertainties.

Fittingly, Te Tangi o te Moa features as cover for visual culture text, The New Zealand Book of Beasts. In their introduction, the authors give impetus for looking, and examining ways of looking, at Aotearoa fauna, writing: "There is no such thing as an objective or neutral point of view... Every position we occupy... is partial in two senses: both incomplete and partisan. The most powerful and enduring of our assumptions about animals are those we are most inclined to accept without question... they have come to seem natural to us, all the more so because we are in the habit of thinking of animals...as part of the biologically given order of things." 
In the era of the Anthropocene, biologically given order is far from a stable phenomenon framed for viewing. In her 2018 analysis, collated biodiversity findings by Sarah P Otto tell us over one in five species of vertebrates, invertebrates, and plants are now at risk of extinction. In Aotearoa, we can woefully claim the world's highest endangerment rates. The concept of a biodiversity crisis, though long enduring in our own country, is yet to tire out. Cited threats include pollution, and changing ecosystems; that is, anthropocentrism and its ensuing climate crises. ${ }^{6}$

With this disruption of stability, enters a necessary unsettling of the systems we have counted upon for understanding and reckoning with endangered animals, communities, and their extinctions. The Interior, as a contemporary meddling of the subject/object relationships of Te Tangi, offers not a space for exclusive gleaning, but rather reciprocity and reflection. As habitable site and scene, observation becomes newly embodied with each visitor's own movements/ paths around or amongst the gathered birds. The act of looking, in turn, is a scrutinised act: humans watching birds, watching humans, watching birds. Attentiveness becomes a necessary contribution by visitors to the work, and the implicated human position is situated not just in an exterior gaze, but also within a broader nonhuman community, enveloped amongst the extinct and near extinct alike.

Such an inward turn of attention, towards our attention, aligns conceptually with photographer Froydi Laszlo's analysis of image making and worlding: "as representations of disappearing life forms continue to be disseminated, we tend to think they are still there... this alone should demonstrate the imperative to complicate the image culture."" She suggests that this begins with acknowledging that "we are accustomed to only feel the loss of that which can be related to our own worlding."8

This presents a challenge, even for those well practiced in the noticing of nonhuman rhythms in relation to their own. Assured reckoning with extinct species (an ever growing number, some never known to begin with), threatened species (some close by, others completely isolated), or even "everyday" species (subsumed into normalcy yet teetering in threatened spaces of climate induced change) presents not only a challenge to attention but also to our compassions, lest we feel relations too weakly or too strongly. The fatigue of maintaining certainty as a solution for unstable systems is highlighted by artist Mark Wilson in his writing on the ecology of uncertainty: with "the need to bring everything into the realm of what is understood and 'known', [leading] us to cut ourselves adrift from things which otherwise would tax us."' This reductionism, Wilson suggests, leaves the certainty-seeker "impoverished in other ways", unable to be "not just in the world, but with the world."'0

In addition to Wilson's "ecologies of uncertainty", I also wish to acknowledge the conceptual supports of Derrida's theory of hauntology, and Jameson's spectrality in my thinking around the arts practices to follow. Speaking to tensions of appearing/disappearing, seeking and losing, and the wax and wane of visual and cultural signifiers, the interplay of uncertainty, ghostliness, and haunting becomes a valuable ecology by which our position alongside at-risk communities can be measured.

Spectrality does not involve the conviction that ghosts exist or that the past (and maybe even the future they offer to prophesy) is still very much alive and at work, within the living present: all it says, if it can be thought to speak, is that the living present is scarcely as self-sufficient as it claims to be; that we would do well not to count on its density and solidity, which might under exceptional circumstances betray us."

I am lead to think of endangerment and extinction as slippery spectralities, with imminent absence sliding alongside (or maybe above, below) present ground. With increasingly expanding and interconnected changes for humans and nonhumans alike, strategies for attention-practicing and making must adapt and shift across variable spatial and temporal scales, whilst also maintaining approachable poetics through which others can emulate their own attentions. The observational process, as a familiar mode of understanding, holds valuable potential for such relational engagement. How can observation and its offered attentions operate across such confronting magnitudes of extinction, endangerment, and flux? The rest of this paper aims to situate the attentive art practices of myself and others along a spectrum of change affecting nonhumans, from the basis of the individual, to community, to species population, to intermingled human/nonhuman communities. 


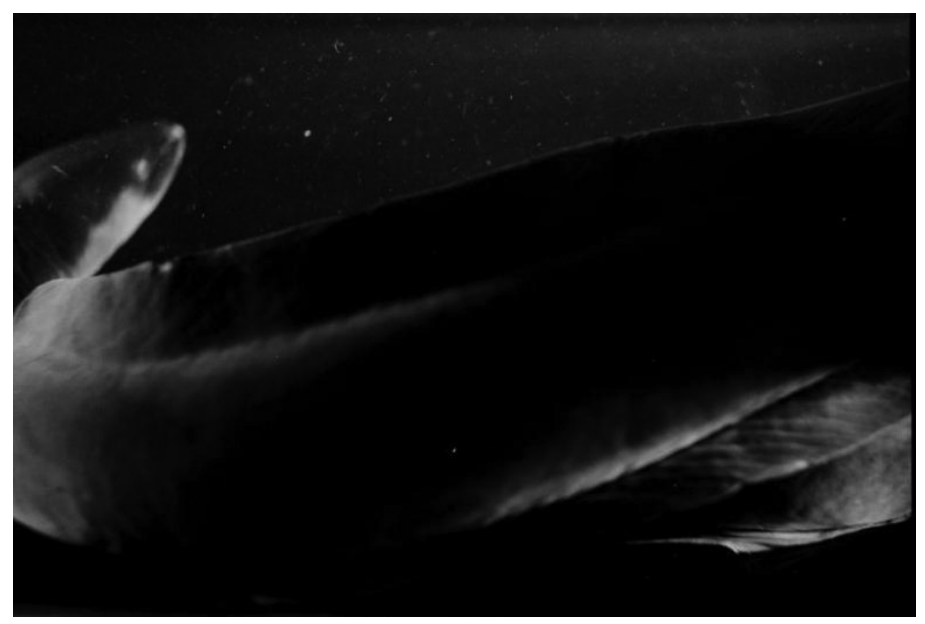

Figure 2. Joyce Campbell, Taniwha V from the Te Taniwha series, 2010, silver gelatin photograph. Accessed June 16 2020. (www.joycecampbell.com/collections/view/23)

Entanglements of site, observational strategies and the spectral animal are evident in the work of photographer Joyce Campbell, who questions our visual position relative to the long-finned eel and its migratory channels in her 2013 series Te Taniwha (Figure 2). Chronically declining in numbers, and subject to a long history of scientific inquiry due to their unobserved periods spent at sea, Campbell approaches the eel (tuna, in te reo Mãori) in context of both past and present uncertainties. The works archive attempts at documenting in equal parts, the mythological water dwelling Taniwha Hinekōrako, the native tuna, and their home site, the politically and ecologically contested waters of Te Reinga. She explains: "Contemporary cameras do not lend themselves to the depiction of mystery [...] by contrast, the nineteenth century techniques of ambrotype and daguerreotype [have] an innate tendency to produce artifacts [...] Campbell has taken photographs of caves, gullies, pools and cascades but her hope is that in the silver we might catch a glimpse of the Taniwha as well."'2 Campbell's records of looking embrace a realm beyond the known, seeking the nature/culture relations of tuna, taniwha and Te Reinga as a series of enduring confluences.

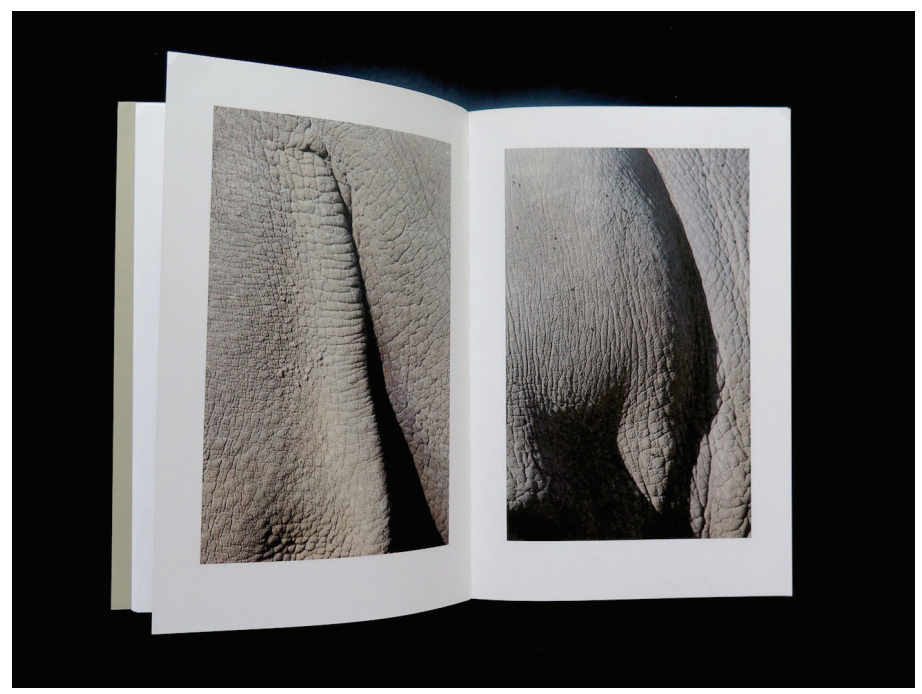

Figure 3. Giovanna Silva, Good Boy 0372, 2016, photobook. Published by Motto Books, accessed I5 June 2020. (www.mottodistribution.com/shop/good-boy-0372.html) 
Italian photographer, designer, and publisher Giovanna Silva continues this thread of welcome unknowing in her photo book Good Boy 0372 (2016, Figure 3), a project wherein attentive practice is directed towards a singular animal representing the finality of their species. Collated over the course of a ten day stay in Kenya, the publication documents time spent with Sudan, North Africa's last surviving male white rhinoceros. Referred to as "good boy" by his keepers, photos of Sudan (now passed away) exist at perhaps the most wavering and immediately spectral boundary. A contemporary echo of Te Tangi o te Moa, Good Boy 0372 is tempting in its high-fidelity photography, a promise of explicit insight to the last moments of a species' time on Earth. The first few images, disclosing every rivulet of Sudan's plated skin, certainly invites such thinking, evoking the visual satisfaction and long relied upon solidity of wildlife photography, which Matthew Brower aptly describes in Developing Animals as access to "deep nature."'3

This access is subverted, however, by extreme close ups throughout the book and incrementally fading glimpses of Sudan, succumbing to blankness by the book's close (Figure 4). Deep access and enlightenment denied, Silva prioritises sprawling, gappy, and intimate mapping. Any project narrative is refused, other than that which considers Sudan's uncertain fate as species representative, and Silva's uneasy role in observing him. Susan Sontag wrote that photography "implies [we] know about the world if we accept it as the camera records it. But this is the opposite of understanding, which starts from not accepting."|' Photographic records such as Silva and Campbell's present artefacts of not-accepting as a method for continued criticality.

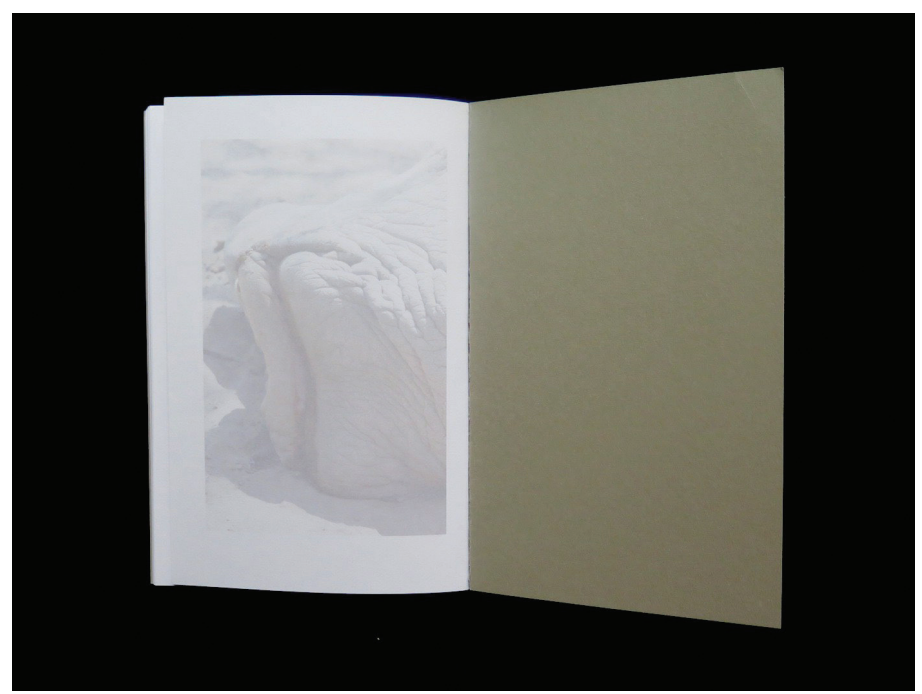

Figure 4. Giovanna Silva, Good Boy 0372, 2016 , photobook. Published by Motto Books, accessed 15 June 2020. (www.mottodistribution.com/shop/good-boy-0372.html)

While the photography of Silva and Campbell evoke the unreliable "density and solidity" of Jameson's spectres, through noncompliant image making in fixed space, Diana Thater's video works introduce uncertainty through the distribution of observational records across physical space. Her 2017 show A Runaway World, exploring threatened African animal communities, offers simultaneous and unfixed records of watching across several intersecting screens and projectors in the gallery space. As Radical As Reality (2017, Figure 5), a four panel projection of (again) Sudan the white rhino, offers a different space to that in Good Boy 0372, with Sudan and his human guards fully disclosed in the camera's framing. The continuity of this posse, however, is visually disrupted by any movement around the work, with footage dispersed into connected but divergent screens. In the same show, A Runaway World (2017, Figure 6) opens the habitat and everyday activities of a local elephant community. Only incrementally further from extinction than Sudan, the elephants are observed as a site-specific collective. In discussion of the show, Thater suggests 
"specific sites are integral to the works...animals are inseparable from their environment...there are many and they intersect."'5 Via spatial and filmic junctions, the works produce flexible tethers between site, threatened animal, and their human observers both in situ and in gallery.

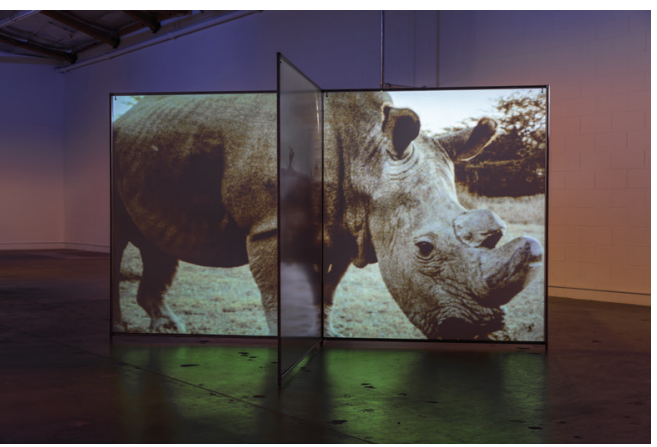

Figure 5. Diana Thater, As Radical as Reality, 2016, video projection. Installation view at The Mistake Room, 2017. Photo by Fredrik Nilsen, courtesy of Thater studio.

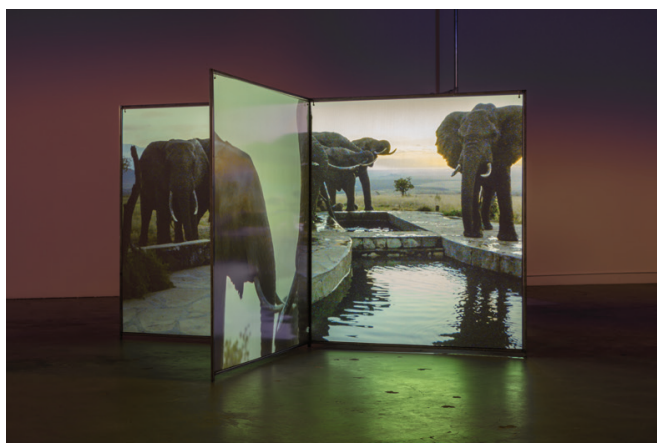

Figure 6. Diana Thater, A Runaway World, 2017, video projection. Installation view at The Mistake Room, 2017. Photo by Fredrik Nilsen, courtesy of Thater studio.

Movements between in-situ populations and their distanced human observers formed the basis of my 2017 project with conservation geneticist Natalie Forsdick and her study of the kaki/black stilt. Isolated to Canterbury's Waitaki basin, kaki are the world's rarest wading birds. They are subject to hybridisation with the self-introduced pied stilt, a phenomenon that threatens possible extinction of their genetic line. Here, uncertainty manifests not only in the kaki's taxonomic status, but in their representation to researchers and the public. As a population, kaki undergo various (somewhat alchemical) representational shifts in relation to their researchers - from real birds, to photos and videos, to blood samples and DNA samples, to computer sequenced code. These shifts occur relentlessly, with conclusions discerned from the various observations fed into an equilibrium of ex-situ research and in-situ management.

The resulting work Kakī, reared and sampled (20I7, Figure 7) explores these shifts through site specific drawings, relaying representational modes of the kaki as noticed, documented and shared between myself and Natalie. Made on the gallery wall, unfixed charcoal drawings were accompanied by shelves that held the dust produced over

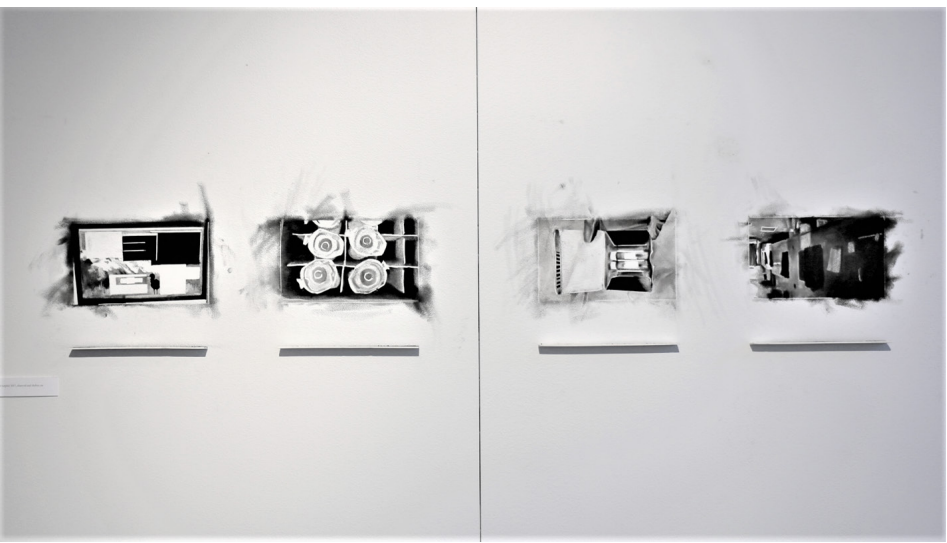

Figure 7. Madison Kelly, Kakī, reared and sampled, 2017, charcoal and shelves on wall. Installation view at the HD Skinner Annex, 2017. Photo by Liam Hoffman.

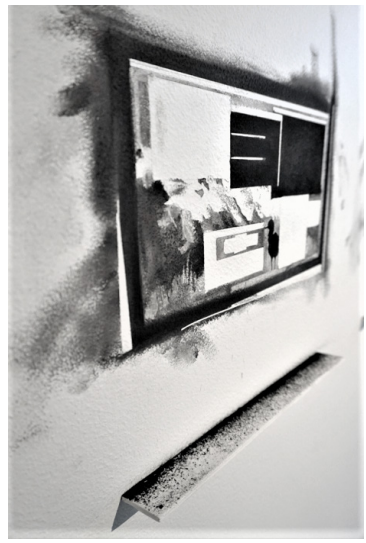

Figure 8. Madison Kelly, Kakī, reared and sampled, 2017, charcoal and shelves on wall (installation detail).

Photo by Liam Hoffman. 
the real-time course of their making (Figure 8). Collected dust revealed the drawing's code, offering up figurative gradients of change between each lab-based kaki trace.

Hybridity, as a process of micro-liminal change, calls for urgent and careful attentions, regularly repeated and compared. In this archiving of incremental shifts, I turn to Clive Humphrey's writing on the observational drawing process. Suggesting that as well as seeing the world, we also "unsee the world....using the process of seeing to confirm our expectations", Humphreys establishes observation and the recording of observation as an "invaluable process for examining accepted knowledge", referencing Berger's notion that "the relation between what we see and what we know is never settled." 16 With great relevance to the concerns at play in this paper, Humphreys elaborates on the observational drawing process as offering repeating and unfixed evidence of "engagement with Other...the continuous act of re-ingestion." ${ }^{\prime 7}$ In each uncertain evaluation, interchanging presentations of the kaki as code or sample, collective or individual, original or hybrid, can be further questioned. If the kakī population presents opportunity for reckoning with change at a species level, what approaches may be adopted for more outwardly shifts - those at scales beyond the individual or taxonomic group?

Arts of Living on a Damaged Planet: Haunted Landscapes of the Anthropocene, discusses "not just the loss of individual species, but of assemblages... an entangled world where bodies are tumbled into bodies, extinction is a multispecies event."'18 The new scales and unpredictability of observing "long evolving co-ordinations and interdependencies"'19, further invite what Mark Wilson describes as "the stumbling blindness...the onotology of the moment... possible re-appraisal and potential." ${ }^{20}$ Multidimensional changes call for multidimensional evocations, reflective of any number of ecologies, economies, or cultures in their making.

The global interplay of ocean organisms, their symbioses, and ensuing cycles under the pressures of ocean acidification became the assemblage of focus for another personal art/science collaboration, this time with parasitologist Colin MacLeod. Researching the impacts of changing parasite behaviours on their intermediate snail hosts under increased $\mathrm{CO}_{2}$ conditions, Colin came to notice a lack of attention towards intersections of parasitology and climate science, despite parasites' foundational role in many community structures. As such, a concern for both Colin and I was the need for multi-faceted methods of approaching linkages between not only the parasite's changing parameters, but also changes occurring in the ocean, and the potential of making these turns accessible to a distanced public.

Ingrid M Parker writing in "Remembering in Our Amnesia, Seeing in Our Blindness", approaches scientific practices through the lens of observation, explaining: "The history of the scientific field of ecology is one of discovery through learning new ways of seeing [... ]in another revolution in awareness, one of the most important developments in ecological science was the rise of manipulative experiment as a tool for studying what could not be seen."'21

Limited by the spatial and temporal scales of real-time ocean acidification, Colin's work with parasites revolves almost entirely around manipulations and simulations of ocean acidification effects on sample parasite and host populations. Lab-based observations via artificial $\mathrm{CO}_{2}$ tanks, microscopy, and fluorescent tagging are utilised to form collective understandings of interacting processes, that which would otherwise remain inaccessible to singular human perspectives. Drawing to Discern Parasites (2018, Figure 9), made in darkness using UV blacklights, a multi camera set up, fluorescent pigment and a water tank, documents the process of repeatedly observing and representing the parasitic life cycle under the changing pressures of fluid dynamics and their eventual obliteration of each drawing over the course of an hour.

The video documentation of drawing attempts, sped up to 17 minutes in total, is installed as a two-channel work, allowing simultaneous viewing of both the surface of water (the site of life cycle drawing) and the tanks' side (where pigment accumulates). As a looping digital document, the noisy green glow builds until no parasitic forms can be clearly discerned. In drawing, assuming the role of observer and image-maker, the call to action lies in a commitment to continuing drawing on an unforgiving ground.Viewers are presented with adjacent options, to commit to seeking 


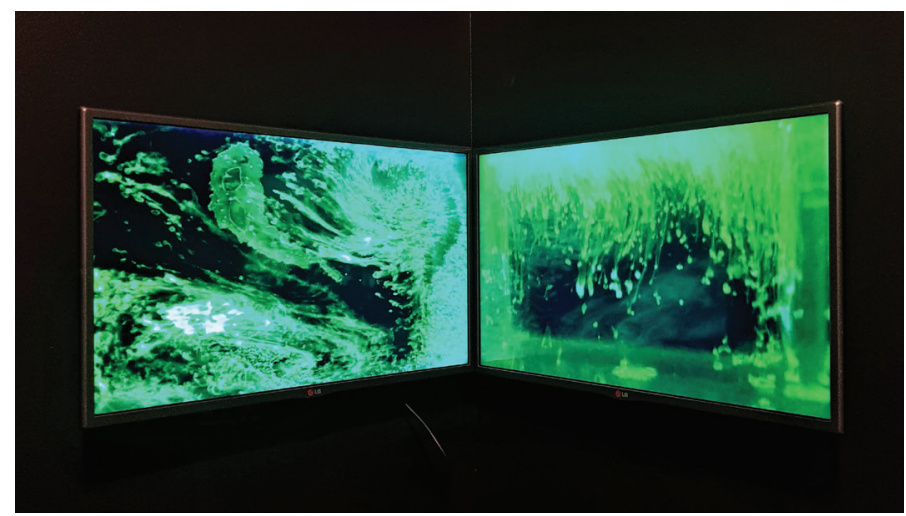

Figure 9. Madison Kelly, Drawing to Discern Parasites, 2018, two channel video documentation of acrylic in water, 16:45. Installation view at the HD Skinner Annex, 2018.

and discerning the life cycle amid growing turbulence, or to observe changes occurring below the surface. Though borne of uncertainties around parasite/host communities, the work eventuated as metaphorical observation of complex, more-than-human phenomena, reliant upon a submersion in unpredictability.

Investigations into communities of change continued in my 2019 work with Jon Lindqvist, a geologist and ichnologist at the University of Otago. Ichnology, the study of trace fossils, occupies a uniquely subjective (and projective) geological niche, speaking more to animal's inferred activities upon the Earth rather than the explicit preservation of their anatomies.

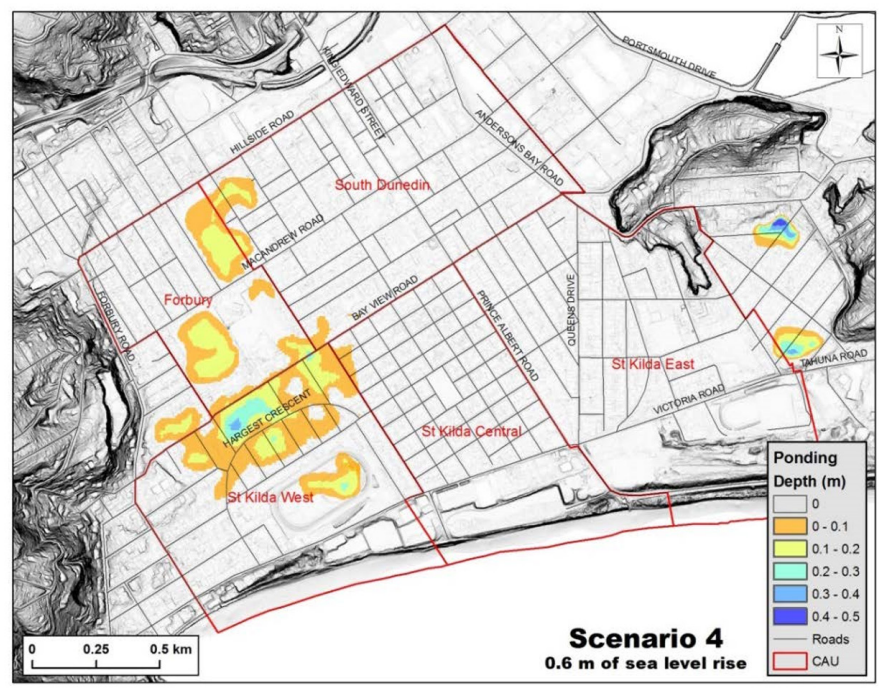

Figure 10. Otago Regional Council,"AAbove-ground ponding for $0.6 \mathrm{~m}$ of mean sea level rise, relative to the 2003-20I5 average", from The Natural Hazards of South Dunedin, 2016, p.52, fig.43. The Musselburgh drawing site is visible as the darkest blue point to the right of the map. Accessed May 152020 (www.orc.govt.nz/media/22 I7/ the-natural-hazards-of-south-dunedin-report-july-20I6.pdf) 
Adolf Seilacher, in Trace fossil Analysis writes "why are there thousands of footprints and not a single bone or tooth of these creatures? This question touches a fundamental problem in paleontology: the fossil record is far from a collection of photographs...there is selective preservation." ${ }^{22}$ As a selective recording process, trace fossilization offers opportunity for reappraising assumptions of nonhuman worlds as readily available or fixed for access.

This thread of re-appraisal was brought to a humble street corner in Musselburgh, South Dunedin. Here, alongside several other saturated topographies in the reclaimed South Dunedin area, Dunedin City Council hazardscapes predict high levels of surface level ponding with increasing sea level rise (Figure 10). Here, speculative interplays of future water, sediment, and life offered fresh terrain for acknowledging the complexity of urban systems affected by global change.

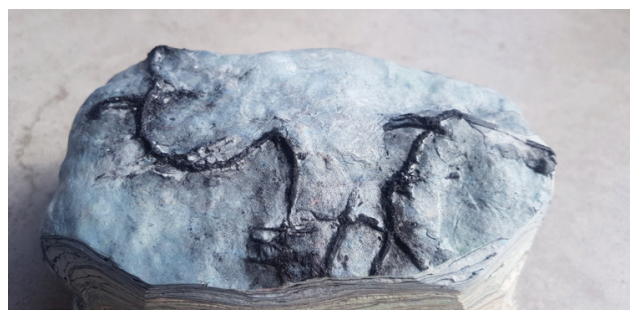

Figure II. Madison Kelly, Present/forthcoming, 2019 (detail), handmade paper, charcoal.

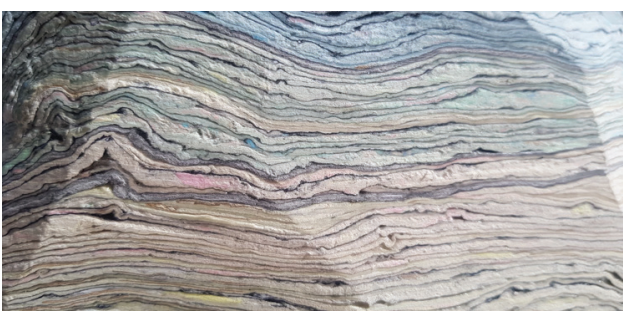

Figure 12. Madison Kelly, Present/forthcoming, 2019 (detail), handmade paper, charcoal.

A compelling aspect of trace fossilisation is the levelling of biotic and abiotic appearances in the fossil record. The toolmarks of twigs dragged along a sandy surface speak with the same mark-making language as the burrowing trails of the wormlike ichnogenus Gyrochorte. This language of a mark reliant record was explored through observational drawing at the threatened site. Activities at different vertical points of the sample area were observed over several months. Paths of travel, encounters or avoidances, movements in the wind (or of the wind), bees flying to flowers, humans and dogs walking past, were all treated as active agents in the observational record. These initial drawings in clay became negative moulds for recycled paper pulp and charcoal dust. Resultant sheets, layered upon one another, form a multidimensional archive of the site (Figure II and 12). The laminations presented are not concerned with concrete data collection, but rather with attention towards networks in flux, as they exist now, and in a nearby future.

The drawings making up the accretion continue as digital archive in an accompanying video (Figure 13), interspersed with video documentation taken in between drawings at the site: bumbling, cellphone footage. These clips do not claim visual apprehension, but rather propose the shaping of what Mark Wilson proposes as "the ontology of the moment." ${ }^{23}$ The digital archive of drawing and video observation, alongside its pseudo fossil, operates equally to evidence site-specific uncertainty and time-based observation, as well as dynamics of change inherent to sea level rise - its flow on effects and their implication of communities both immediate and distant. Drawings situated at the beginning of the paper layers introduce ever

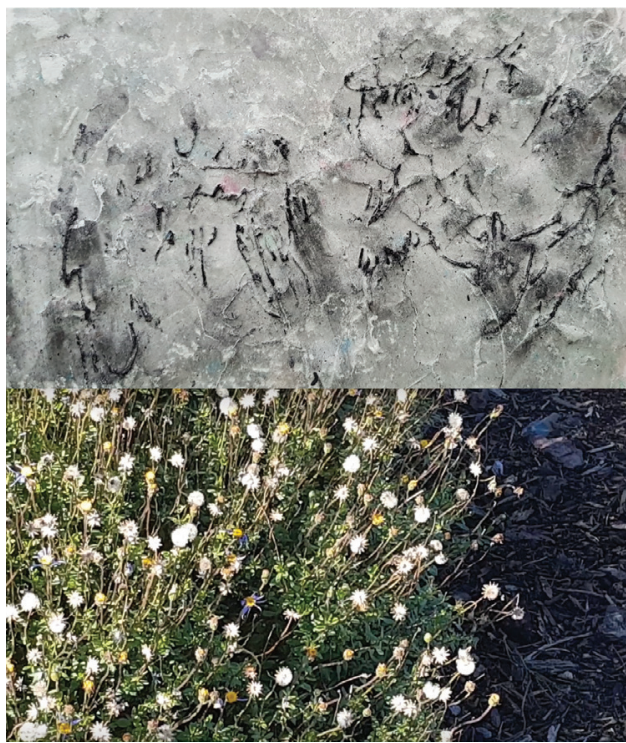

Figure 13. Madison Kelly, Present/forthcoming, 2019 (video still composite), handmade paper, charcoal, and video, 6:05. 
increasing undulations to those that follow. Having now, a year later, read William Connolly's "Extinction Events and Entangled Humanism", I see new functions of uncertainty in the pulpy rock, material echoes of his described passive climate change nihilisms, where "second order residues" re-emerge in "higher order beliefs... [subsisting] as uncanny reminders 24" $^{2}$ of Othered changes. At home, in the middle of COVID-19 lockdown, I have started trying to draw shadows of the garden's flora and fauna throughout the day, involving myself further into muddled ghosts and new residual anxieties.

Anxieties aside, I feel most lucid in this de-stabilised looking, and likewise feel with interest its call for action: the call to look again. In our relations with threats, endangerments, and extinctions, there exists a productive in-between, a movement around mourning and hope that informs our conception of the nonhuman communities we have implicated in our actions. In an unstable era, it is imperative we continue to look upon and communicate upon equally unstable ground, provoking new ways of visualising those we cannot, or may not see again.

Madison Kelly graduated with honours (majoring in drawing) from the Dunedin School of Art in 20 17. Her Ōtepoti based practice seeks understandings of nonhuman/human relations, focusing on drawing's capacity for evoking records of time and attention towards threatened species and sites.

I Sorawit Songsataya, The Interior, 2019, fibreglass, polyester resin, acrylic lacquer, Oamaru stone. Carver: Brett Tutauanui Keno (Ngāti Ranginui, Ngāi te Rangi, Ngāi Tahu). Commissioned by Auckland Art Gallery Toi o Tāmaki, 2019, 2019, Auckland Art Gallery, Toi o Tāmaki, https://www.aucklandartgallery.com/whats-on/exhibition/sorawit-songsataya-the-interior.

2 'Sorawit Songsataya:The Interior', Auckland Art Gallery Toi o Tamaki (blog), n.d., https://www.aucklandartgallery.com/whats-on/ event/sorawit-songsataya-the-interior?q=\%2Fwhats-on\%2Fevent\%2Fsorawit-songsataya-the-interior.

3 Margaret McFall-Ngai, "Noticing Microbial Worlds:The Postmodern Synthesis in Biology," in Arts of Living on a Damaged Planet: Ghosts and Monsters of the Anthropocene (Minneapolis: University of Minnesota Press, 2017), 52.

4 McFall-Ngai, 52.

5 Annie Potts, Philip Armstrong, and Deidre Brown, A New Zealand Book of Beasts: Animals in Our Culture, History and Everyday Life (Auckland, New Zealand: Auckland University Press, 2013), 4.

6 Department of Conservation, New Zealand's Sixth National Report to the United Nations Convention on Biological Diversity (Wellington, New Zealand: Department of Conservation, 2018 20I4), https://www.doc.govt.nz/globalassets/documents/ about-doc/role/international/nz-6th-national-report-convention-biological-diversity.pdf.

$7 \quad$ Froydi Laszlo, "Place and World: The Photographs of Bryndis Snaebjornsdottir and Mark Wilson as Environmental Photography," in You Must Carry Me Now: The Cultural Lives of Endangered Species, ed. Mark Wilson and Ron Broglio (Arizona, USA: 284 Publishing, 2015), 145.

8 Laszlo, 143.

9 Mark Wilson, Beyond Control-towards and Ecology of Uncertainty (University of Cumbria, 20 I 2), 3.

10 Wilson, 3.

II Colin Davis, "Hauntology, Spectres and Phantoms," French Studies 59, no. 3 (2005): 373.

12 Joyce Campbell, Te Taniwha (2013), http://www.joycecampbell.com/collections/view/23. 
13 Matthew Brower, Developing Animals: Wildlife and Early American Photography (Minneapolis: University of Minnesota Press, 2010), xiv.

14 Susan Sontag, On Photography (New York: Penguin, 1977), 23.

I5 Diana Thater, Call of the Wild:Video installation artist Diana Thater's Runaway World, n.d., https://baku-magazine.com/art/ diana-thater-runaway-world/.

I6 Clive Humphreys, 'Eat Up Your Greens-Drawing as Re-Ingesting the World,' Scope: Contemporary Research Topics I Art (2006): II.

17 Humphreys, I5.

I8 Elain Gan et al., 'Introduction: Haunted Landscapes of the Anthropocene,' in Arts of Living on a Damaged Planet: Ghosts and Monsters of the Anthropocene (Minneapolis, USA: University of Minnesota Press, 2017), 3.

19 Gan et al., 3.

20 Wilson, 'Beyond Control-towards and Ecology of Uncertainty', 2.

21 Ingrid M. Parker, 'Remembering in Our Amnesia, Seeing in Our Blindness,' in Arts of Living on a Damaged Planet: Ghosts and Monsters of the Anthropocene (University of Minnesota Press, 2017), 164.

22 Adolf Seilacher, Trace Fossil Analysis (Berlin, Germany: Springer, 2007), I.

23 Wilson, 'Beyond Control-towards and Ecology of Uncertainty', 3.

24 William Connolly, 'Extinction Events and Entangled Humanism,' in After Extinction, ed. Richard Grusin (University of Minnesota Press, 2018), 14. 